\title{
Antoine Fongaro, Bibliographie de Gide en Italie (1895-1963)
}

\section{Emanuele Kanceff}

\section{Q OpenEdition}

1 Journals

\section{Edizione digitale}

URL: https://journals.openedition.org/studifrancesi/41092

DOI: 10.4000/studifrancesi.41092

ISSN: 2421-5856

\section{Editore}

Rosenberg \& Sellier

\section{Edizione cartacea}

Data di pubblicazione: 1 juillet 2004

Paginazione: 218

ISSN: 0039-2944

\section{Notizia bibliografica digitale}

Emanuele Kanceff, «Antoine Fongaro, Bibliographie de Gide en Italie (1895-1963)», Studi Francesi [Online], 142 (XLVIII | I) | 2004, online dal 30 novembre 2015, consultato il 09 septembre 2021. URL: http:// journals.openedition.org/studifrancesi/41092; DOI: https://doi.org/10.4000/studifrancesi.41092

Questo documento è stato generato automaticamente il 9 septembre 2021.

\section{(c) (i) (9)}

Studi Francesi è distribuita con Licenza Creative Commons Attribuzione - Non commerciale - Non opere derivate 4.0 Internazionale. 


\title{
Antoine Fongaro, Bibliographie de Gide en Italie (1895-1963)
}

\author{
Emanuele Kanceff
}

\section{NOTIZIA}

ANTOINE FONGARO, Bibliographie de Gide en Italie (1895-1963). Publications de l'Institut Français de Florence, $\mathrm{II}^{\mathrm{e}}$ série, Florence, Institut Français de Florence, nouvelle édition, 2000, pp. 288 (Collection d'études bibliographiques, 16).

Abbiamo già detto a suo tempo il nostro pensiero e la nostra grata stima per questa ineccepibile bibliografia gidiana di Antoine Fongaro, pubblicata nell'edizione originale presso Sansoni nel 1963. Ora sentiamo il dovere di riprendere il discorso, in occasione della nuova edizione, che porta la data del 2000 e che non è, come spesso avviene, una ripresa - con qualche leggero ritocco - dell'edizione precedente, bensì un'opera interamente refusa e pressoché raddoppiata, nonostante l'autore non abbia variato gli estremi cronologici del periodo considerato (1895-1963), ritoccata nell'introduzione e nell'annotazione, arricchita notevolmente nei documenti inediti. Uno strumento moderno, informatissimo, rigoroso, indispensabile per gli studiosi. 